\title{
Estudo exploratório sobre satisfação e preferências dos usuários: mecanismos de interação em infografia para smartphones
}

\author{
Exploratory study about user satisfaction and preferences: \\ interaction mechanisms in infographics for smartphones
}

Infografia, mobile, smartphones

\begin{abstract}
Esse artigo é uma síntese de uma pesquisa exploratória que objetivou identificar mecanismos de interação em infográficos em smartphones, verificando como os usuários interagem com eles e suas preferências no que tange aos aspectos de interação. O método consistiu em revisão de literatura, estudo analítico e ensaio de interação. Desenvolveu-se instrumentos necessários para análise dos infográficos, e o questionário do Ensaio de Interação. Fez-se análise de 27 infográficos no suporte smartphone, e realizou-se ensaios de interação com 14 usuários. Como resultados, constatou-se: a carência de literatura acerca da temática; infográficos para smartphones não têm autonomia; são muito parecidos entre si; e não exploram as vantagens do meio digital. Por fim, foi constatado que os usuários preferem infográficos simples, concisos, intuitivos, interativos, animados, e "dinâmicos".
\end{abstract}

Infography, mobile, smartphones
This article is a synthesis of an exploratory study that aimed to identify interaction mechanisms in infographics on smartphones, verifying how users interact with them and their preferences regarding aspects of interaction. The method consisted of a literature review, an analytical study and an interaction test. Necessary instruments were developed for the analysis of the infographics, and the questionnaire for the Interaction Test. An analysis of 27 infographics was performed on the smartphone support, and interaction tests were performed with 14 users. Results revealed: the lack of literature on the subject; infographic for smartphones don't have autonomy; they are very similar to each other; and don't exploit the advantages of the digital medium. Finally, we found that users prefer simple, concise, intuitive, interactive, animated, and "dynamic" infographics.

\section{Introdução}

Estima-se que até 2020 os dispositivos móveis representem dois terços da atividade online (REILlY, 2017). Esse crescimento do mercado de dispositivos móveis tem gerado oportunidades comerciais e sociais. Portanto, desenvolver soluções voltadas aos smartphones representa 
um meio eficaz de atingir o público-alvo desejado (TIBEs; DIAS; ZEM-MASCARENHAS, 2014).

Nesse contexto, a visualização da informação em smartphones vem ganhando espaço e a infografia vem sendo utilizada com diferentes propósitos nos dispositivos móveis. Conforme Carvalho e Aragão (2012), a infografia tem seu uso voltado principalmente à comunicação (jornais, revistas, mídias impressas ou digitais), devido à natureza informacional dos infográficos. Mesmo a infografia estando relacionada a uma tradição da linguagem jornalística, ela não se limita a essa área (AMARAL, 2010; FASSINA, 2011). A literatura também aponta que a infografia é utilizada principalmente no âmbito educacional e jornalístico (FASSINA, 2011; MORAES, 2013; MIRANDA; ANDRADE, 2017).

Rodrigues (2011) ressalta que a infografia se mostra suscetível a mudanças, formatos e linguagens, buscando adaptar-se aos novos suportes tais como tablets e smartphones. Entretanto, nem sempre os infográficos são planejados pensando nesse suporte. Geralmente os infográficos são adaptados/redimensionados de outras telas, o que pode ocasionar problemas de legibilidade e navegação, por exemplo. Ainda, tem-se a questão da miniaturização dos elementos das interfaces, gerando problemas ergonômicos e de usabilidade (KRONE, 2013; PADOVANI; NAPO, 2015).

Apesar se tratar de área pertinente ao design, a infografia é abordada frequentemente sob a perspectiva jornalística (CARVALHO; ARAGÃO, 2012). Adotar apenas essa perspectiva pode gerar lacunas quanto à perspectiva de design de infografia para smartphones, tanto no que se refere às especificidades técnicas de planejamento e design, quanto às recomendações para desenvolvimento de infografia para esse suporte (e.g., layout, interação, navegação).

Diante do exposto, o presente estudo teve como objetivos identificar mecanismos de interação em infográficos em smartphones, verificar como os usuários interagem com esses infográficos e quais são suas preferências no que tange aos aspectos de interação.

\section{Infografia digital e interativa}

\subsection{Conceituação de infografia}

As definições para o termo infografia "são amplas e diversas" (RODRIGUEs, 2009, p. 34), e não há consenso entre os autores (RIBAS, 2004; LIMA, 2009; RODRIGUES, 2009; FASSINA, 2011 apud MIRANDA, 2013, p. 25).

Neste estudo foi adotada a definição de Lima (2009), que conceitua infografia como "uma peça gráfica que utiliza simultaneamente a linguagem verbal gráfica, esquemática e pictórica, voltada prioritariamente à explicação de algum fenômeno" (LIMA, 2009, p. 23).

Essa definição considera não apenas a relação imagem/texto, mas também diferentes "modos de simbolização das imagens", e sua 
simultaneidade junto à linguagem verbal gráfica (i.e., texto escrito) (MIRANDA, 2013). Já o termo "digital" diz respeito ao meio em que o infográfico se apresenta (impresso ou digital).

\subsection{Classificações para infografia}

A classificação da infografia e os recursos nela utilizados variam de acordo com o meio e suporte em que se encontra. Essas categorias aparecem nos diversos contextos de uso da infografia, e a escolha de qual tipo utilizar varia de acordo com o conteúdo a ser expresso, meio, e o público-alvo a que se destina. O quadro-síntese a seguir resume parâmetros classificatórios para infografia e seus respectivos tipos:

Quadro 1 Quadro-Síntese de classificações para infografia. Fonte: elaborado pelas autoras (2019).

\begin{tabular}{lll}
\hline Autor & Parâmetros classificatórios & Tipos \\
\hline $\begin{array}{l}\text { Tufte } \\
\text { (1983) }\end{array}$ & Classes de apresentações gráficas & $\begin{array}{l}\text { linha do tempo, mapas de dados, } \\
\text { gráficos relacionais e narrativas } \\
\text { espaço-temporais }\end{array}$ \\
\hline $\begin{array}{l}\text { De Pablos } \\
(1999)\end{array}$ & Conteúdo do infográfico & $\begin{array}{l}\text { descritivos, de apresentação, } \\
\text { explicativos, de informação } \\
\text { quantitativa, investigativo, de } \\
\text { reconstituição, de fatos }\end{array}$ \\
\hline $\begin{array}{l}\text { Nichani; } \\
\text { Rajamacknicam } \\
(2003)\end{array}$ & Categorias de comunicação & $\begin{array}{l}\text { narrativas, instrutivas, } \\
\text { explorativas e simulativas }\end{array}$ \\
\hline $\begin{array}{l}\text { Velho } \\
(2007)\end{array}$ & Tipo de infográfico & $\begin{array}{l}\text { estático, animado, hipertextual, } \\
\text { hipermídia }\end{array}$ \\
\hline $\begin{array}{l}\text { Gianella } \\
(2014)\end{array}$ & Modos de organização & $\begin{array}{l}\text { quantitativo, grupal, conectivo, } \\
\text { temporal, geográfico }\end{array}$ \\
\hline
\end{tabular}

\subsection{Infografia digital}

Para Rodrigues (2011), a infografia se adequa e se remodela frente às novas linguagens e condições abertas na web. Mostra-se um produto suscetível a mudanças tanto em formatos quanto em linguagens, visando se adaptar-se aos novos suportes, como tablets e smartphones.

Segundo Miranda (2013), a infografia digital apresenta diversas potencialidades, podendo utilizar como diferenciais recursos de áudio, animação e interação. Para o autor, no contexto da infografia digital, animação consiste em "apresentação sucessiva de uma série de imagens analógicas ou digitais que modificam sua estrutura visual ao longo do tempo, simulando mudança através da percepção do observador" (MIRANDA, 2013, p. 44). 
Como exemplo de animação em infografia digital, tem-se:

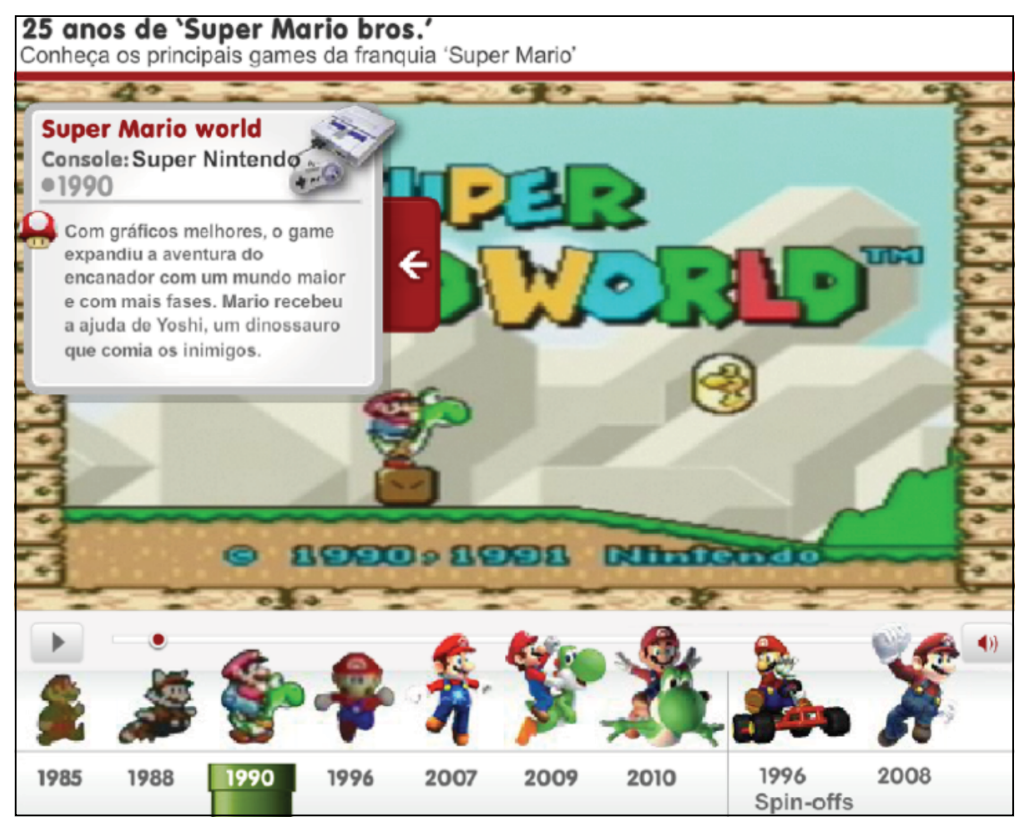

Figura 1 Infografia digital contendo animações. Fonte: http://goo.gl/ qMgGE. (c) Todos os direitos reservados a G1.

Em relação à interação, Miranda (2013, p. 61) conceitua como:

Troca de mensagens entre usuário e sistema de informação mediada por uma interface digital, na qual ações seletivas do usuário acarretam respostas do sistema perceptíveis através da alteração na forma e/ou conteúdo da interface.

Como exemplo de interação em infografia digital, tem-se:

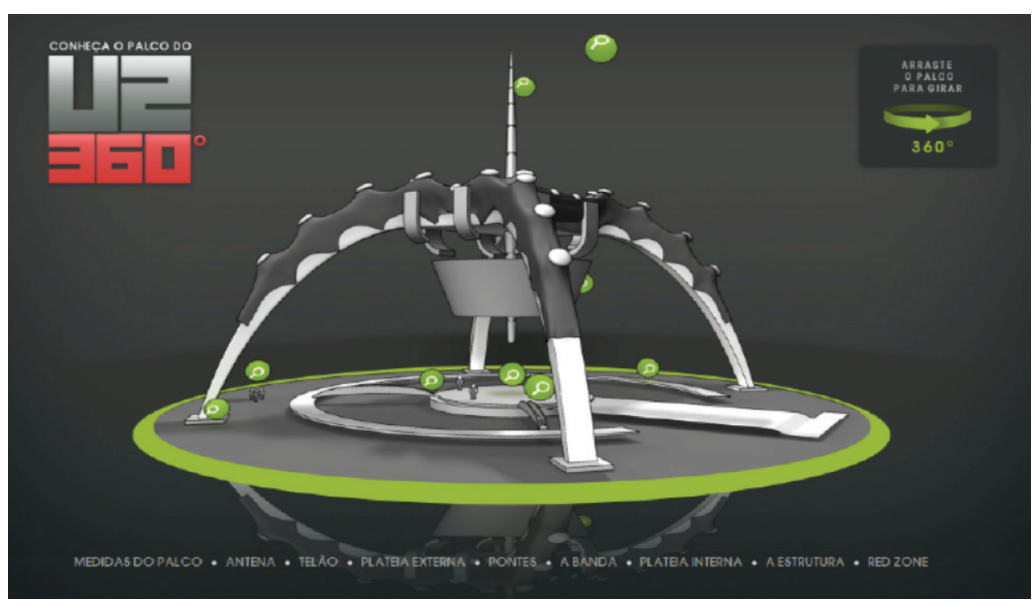

Figura 2 A infografia digital permite ao usuário clicar e rotacionar o palco da banda U2. Fonte: http://goo.gl/zwVA9. (c) Todos os direitos reservados a iG. 
Para Giannella (2014), o que permitiu a melhoria da infografia e diversificação de suas representações foi a informatização das redações e a consolidação da modalidade comunicacional digital e online. Para a referida autora, o desenvolvimento tecnológico favoreceu novas possibilidades para infográficos digitais e online, destacando-se:

- Multimidialidade: qualidade que caracteriza a conjugação de formatos de mídias tradicionais (imagem, texto, som, etc), e sua posterior circulação em múltiplas plataformas e suportes, descrevendo uma situação de complementaridade.

- Hipertextualidade: qualidade que permite interconexões entre textos compreendidos como blocos de informação, através de hyperlinks.

- atualização contínua: qualidade que caracteriza a possibilidade de produtos serem continuamente atualizados pelos produtores de informação, permitindo acompanhamento e monitoramento de assuntos de maior interesse.

- uso de base de dados: introdução da base de dados, cruzamento de dados, maior grau de interatividade, personalização do conteúdo por parte do usuário e usos de softwares baseados na web.

- animações e interatividade: refere-se ao uso de animações em vídeo (de transição ou outras formas), e interatividade refere-se à qualidade que permite aos usuários tornar-se mais diretamente ativos no processo jornalístico.

\subsubsection{Interação com infográficos em smartphones}

Segundo Rodrigues (2011), a interatividade é característica fundante no que diz respeito às novas criações de formatos e composições infográficas, não se restringindo a uma característica, mas atuando como ferramenta vital para a construção de infográficos mais interativos e dinâmicos na web.

De acordo com Miranda (2013), uma parte da literatura sugere que em casos específicos a interação pode ser benéfica para a percepção, compreensão e fatores emocionais dos usuários, porém, outros estudos recomendam cautela. Cairo (2008b), pontua que "um excesso de possibilidades de manipulação dos dados pode confundir o leitor e tornar a navegação um suplício [...]” (CAIRO, 2008b, p. 6). Em geral, considera-se que a interação será benéfica enquanto a carga cognitiva demandada do usuário não seja alta (sCHWAN; RIEMPP, 2004).

No contexto da infografia, Andrade (2014) pontua que as animações e interações impactam positivamente na preferência dos usuários. Porém, menciona que em situações específicas a interação pode não ser benéfica como auxílio para a compreensão de conteúdos: quando é necessária alta carga cognitiva para assimilação do conteúdo. De acordo com o autor, 
Na literatura sobre aprendizagem cognitiva é difundido o conceito de que o ser humano possui uma memória de trabalho com capacidade limitada, a qual pode ser sobrecarregada facilmente (e.g. MILLER, 1956; BADDELEY; HITCH, 1974; SWELLER, 1988; MAYER, 1997) (ANDRADE, 2014, p. 66).

[...] estudos como os de Lowe (2004) atentam que a interação pode tornar a atividade mais complexa ao aumentar o número de atividades que devem ser planejadas e lembradas pelo usuário. Neste sentido Hollender et al. (2010) indica que a carga cognitiva acarretada por essa complexidade pode ser amenizada se houver um bom planejamento destas interações (ANDRADE, 2014 p. 54).

[...] Betrancour (2005), explica que animações combinadas com interatividade em ambientes multimídia promovem uma melhor compreensão de informações dinâmicas como trajetórias, transformações movimentos tanto de domínios físicos como abstratos. Porém, a autora ressalta a necessidade de adequar estes recursos para que eles sejam de fato benéficos (ANDRADE, 2014 p. 79).

Nesse sentido, Andrade (2014) elabora um quadro que relaciona os autores, os aspectos observados em seus estudos e os aspectos que foram identificados como influenciados pela animação e interação na literatura:

Quadro 2 Relação entre aspectos observados × aspectos influenciados pela animação e interação. Fonte: Andrade (2014, p. 54).

\begin{tabular}{lll}
\hline Autores & Aspectos observados & Aspectos influenciados \\
\hline Pottes (2012) & $\begin{array}{l}\text { A influência que a flexibilidade de } \\
\text { interação gera na visualização da } \\
\text { informação e realização da tarefa }\end{array}$ & $\begin{array}{l}\text { Os mecanismos de interação podem evitar que os usuários } \\
\text { cometam erros, já que existe a possibilidade de retornar às } \\
\text { etapas da informação que deixaram dúvidas }\end{array}$ \\
\hline Spinillo et al. (2010) & $\begin{array}{l}\text { Compreensão de uma instrução } \\
\text { visual animada variando em tempo de } \\
\text { apresentação dos passos }\end{array}$ & $\begin{array}{l}\text { Expectativa por parte dos participantes de que a interface } \\
\text { permitisse interação }\end{array}$ \\
\hline Souza e Dyson (2008) & $\begin{array}{l}\text { Flexibilidade da interação frente a } \\
\text { percepção dos usuários }\end{array}$ & $\begin{array}{l}\text { Instruçães animadas com diferentes níveis de interação são } \\
\text { bem vindas por grande parte dos usuários }\end{array}$ \\
\hline $\begin{array}{l}\text { Meyer, Rasch e } \\
\text { Schnotz (2010) }\end{array}$ & $\begin{array}{l}\text { Efeitos do controle da velocidade da } \\
\text { animação no aprendizado }\end{array}$ & $\begin{array}{l}\text { A interação não é necessariamente benéfica quando } \\
\text { permite o usuário mudar vistas e velocidade da animação } \\
\text { pois eles podem perder informações importantes só } \\
\text { observadas em determinada vista a determinada velocidade }\end{array}$ \\
\hline $\begin{array}{l}\text { Lowe (2004) } \\
\text { De que maneira aprendizes } \\
\text { inexperientes questionam as } \\
\text { animações por meio da interação }\end{array}$ & $\begin{array}{l}\text { A simples presença de interação pode não ser benéfica } \\
\text { em ajudar os aprendizes novatos a extrair informações } \\
\text { relevantes já que estes não sabem quais são informações } \\
\text { fundamentais as quais eles tem que questionar }\end{array}$ \\
\hline $\begin{array}{l}\text { Schwan e Riempp } \\
\text { (2004) }\end{array}$ & $\begin{array}{l}\text { Se a visualização dinâmica pode } \\
\text { ganhar alum efeito adicional ao ser } \\
\text { combinada com interação }\end{array}$ & $\begin{array}{l}\text { Apresentações dinâmicas acrescidas de interação podem } \\
\text { acelerar o processo de aquisição do conhecimento }\end{array}$ \\
\hline
\end{tabular}


Miranda (2013) menciona que, de modo geral, os infográficos por ele pesquisados utilizavam apenas um ou dois tipos de objetos de interação concomitantemente e que a interação era pouco explorada. Pontua que os infográficos analisados apresentavam formas não sofisticadas de interação e pouco aproveitavam esses recursos. Posteriormente, Andrade (2014) também identificou uso limitado de recursos interativos, com interações simples.

Ainda conforme Miranda (2013, p. 133)

Apesar da evolução tecnológica da última década, a interação na infografia digital ainda se parece com aquela utilizada em portais de notícias do final dos anos 1990 (CAIRO, 2008a; RODRIGUES, 2009), isto é, predominantemente sequencial e com navegação através de botões.

Tem-se ainda a adaptação de recursos oriundos do meio impresso para o meio digital, em que muitas vezes as limitações e vantagens que o meio digital oferece não são consideradas em sua plenitude.

Para Waller (2012), embora a Internet seja geralmente considerada uma experiência mais interativa, o leitor da versão online tem a experiência mais linear no nível da página. O autor afirma que o mundo digital ainda não terminou de evoluir formatos utilizáveis para gerenciar a dimensão conversacional de sites. O mesmo formato é usado para alguns comentários em um blog quanto a milhares de comentários em um jornal nacional: uma página de rolagem contínua (às vezes cortada em várias páginas), conteúdo não classificado e não editado.

Com relação ao viés digital, a literatura aponta que ocorre transposição do meio impresso para o meio digital (RODRIGUES, 2011), permitindo a exploração de recursos interativos e/ou animações nos infográficos, por exemplo. Porém, nem sempre esses recursos são explorados, e muitas vezes o conteúdo é simplesmente transposto para a nova tela, sem o devido planejamento que o suporte requer. Um exemplo é a tendência tecnológica de priorizar a miniaturização, que implica em problemas ergonômicos (KRONE, 2013).

\subsubsection{Considerações sobre infografia em smartphones}

A infografia em smartphones ainda é um campo novo e em expansão. Nossa revisão de literatura não apontou parâmetros específicos para análise de infográficos mobile. Os três principais parâmetros referentes ao universo web apontados pela literatura são: multimidialidade, hipertextualidade e interatividade, referentes ao jornalismo online.

Primo (2011) e Rodrigues (2011) pontuam que a infografia mobile requer linguagem própria e design específico. É necessário nova dinâmica e nova experiência de leitura. Para eles, a infografia mobile vai além do aspecto estético do design, e o trabalho conjunto entre infografistas e desenvolvedores é fundamental para o trabalho dentro das especificidades da plataforma, de modo a melhor explorar suas nuances. 
As autoras Padovani e Napo (2015, p. 43) lembram que "uma interface móvel não é uma interface de desktop, com o mesmo paradigma e todos seus elementos em tamanho reduzido."

Quanto à visualização em telas pequenas, para Fonseca, Navarro e Redondo (2011) a restrição mais importante é o tamanho da tela. Isso condiciona a quantidade de informação que o olho humano pode perceber, sendo necessário projetar de maneira adequada a quantidade de informação que se pretende mostrar.

Para Barrio (2014), necessita-se de distribuição organizada e de otimização de imagens para apresentar conteúdo de forma eficaz em dispositivos móveis. Barrio (2014) sugere projetar uma estratégia de conteúdos só para os dispositivos móveis, diferente da página vista no computador ou tablet. Ela pontua ser fundamental compreender e criar linguagens específicas para o meio. O smartphone não é meramente um novo suporte para os conteúdos digitais, mas abre portas para novos formatos de conteúdo.

\section{Método}

O presente estudo combina técnicas de coletas de dados com abordagem qualitativa e exploratória. Na primeira parte da pesquisa utilizou-se uma combinação de revisão de literatura e pesquisa documental, e na segunda parte utilizou-se estudo analítico, e ensaio de interação (com observação, questionário e entrevista).

A Figura 3 resume as etapas dessa pesquisa: a partir da pergunta de pesquisa elaborou-se a fundamentação teórica; em seguida houve o estudo analítico dos paradigmas de interação; depois foi realizado o

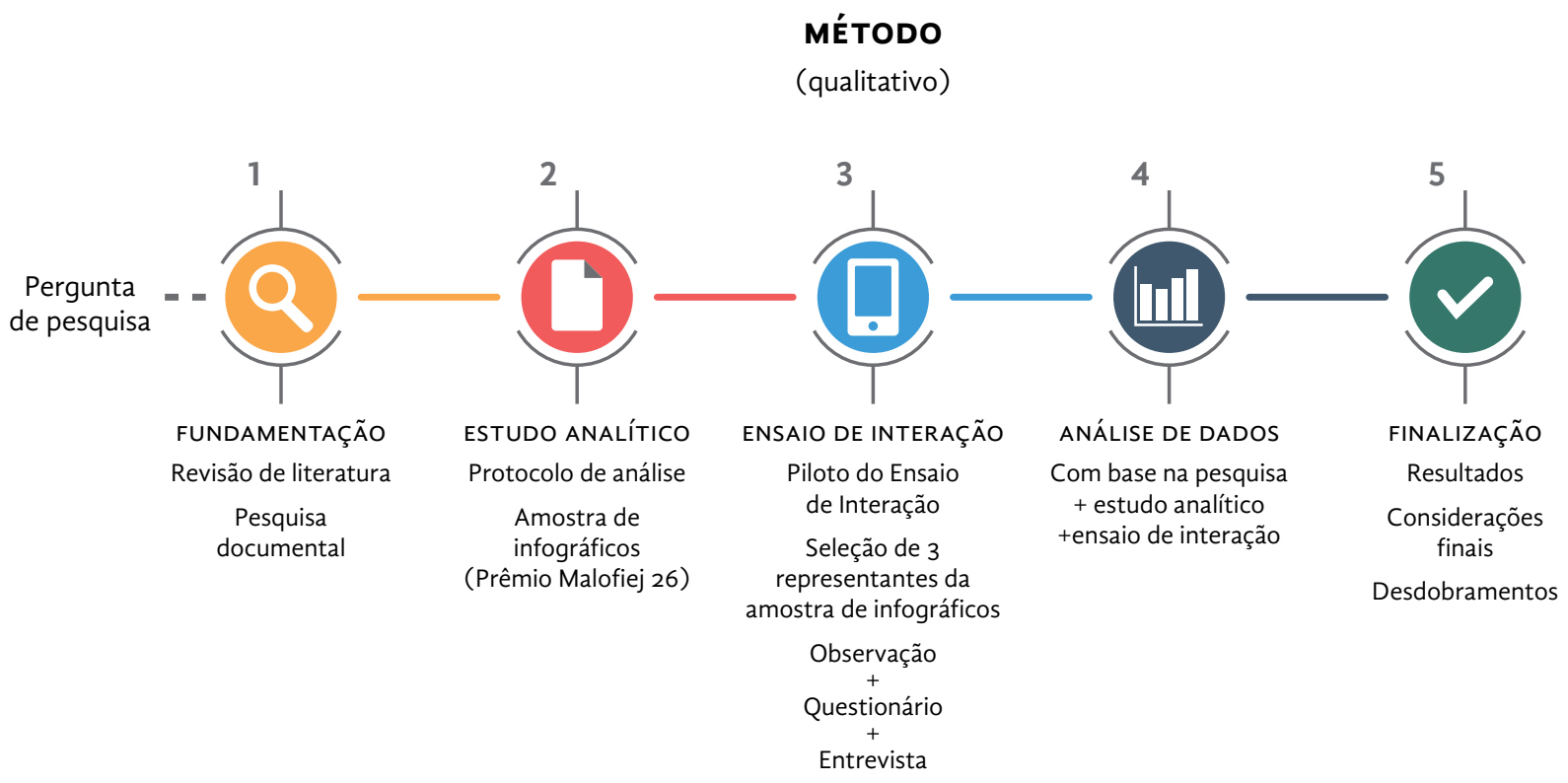

Figura 3 Representação gráfica de síntese do método da pesquisa. Fonte: elaborado pelas autoras (2019). 
ensaio de interação com os usuários; foi realizada análise dos dados; e finalização da pesquisa com reunião de seus possíveis desdobramentos.

As técnicas de coleta utilizadas para a parte documental da pesquisa consistiram em Revisão de literatura, e pesquisa documental. Visou-se levantar pesquisas realizadas acerca dos infográficos para smartphones. Buscas foram realizadas nas principais bases de dados nacionais e internacionais acessadas através do sistema CAPES, e repositório da UFPR. Pesquisou-se em periódicos Qualis A, e periódicos da área de pesquisa. Como fontes da pesquisa documental teve-se: blogs de design, sites de institutos de pesquisa, manuais de desenvolvimento, sites de empresas de visualização de dados, blogs sobre data visualization, blogs de User Experience, blogs sobre User Interface, redes de compartilhamento de imagens, livros, etc.

\subsection{Estudo analítico}

O estudo analítico teve uma amostra de 27 infográficos gratuitos encontrados em versões para smartphone no sistema operacional Android, selecionados a partir do Prêmio Malofiej 26 na categoria online graphics. Foi desenvolvido protocolo de análise específico para a análise descritiva da amostra de infográficos. Esse instrumento contemplou aspectos como identificação, contexto e descrição geral do infográfico, relação com usuário, arquitetura da informação e interação, e navegação. O objetivo foi extrair dados de como se constituem os infográficos analisados, com foco em interação.

Os parâmetros do protocolo de análise consistiram em 5 grandes partes, subdivididas conforme o Quadro 3:

Quadro 3 Parâmetros do protocolo de análise utilizado no Estudo Analítico. Fonte: elaborado pelas autoras (2020).

\begin{tabular}{|c|c|}
\hline Parâmetros & Aspectos analisados \\
\hline \multirow[t]{6}{*}{ Identificação } & Data de acesso \\
\hline & Área temática \\
\hline & Conteúdo \\
\hline & Veículo de publicação \\
\hline & Link \\
\hline & Miniatura do infográfico para facilitar a identificação \\
\hline \multirow[t]{5}{*}{ Contexto e descrição geral } & Contexto da apresentação \\
\hline & Modos de representação predominantes \\
\hline & Categoria do infográfico \\
\hline & Agrupamento \\
\hline & Multimídia \\
\hline \multirow[t]{2}{*}{ Relação com o usuário } & Personalização \\
\hline & Adaptatividade \\
\hline
\end{tabular}


Quadro 3 Parâmetros do protocolo de análise utilizado no Estudo Analítico. Fonte: elaborado pelas autoras (2020).

\begin{tabular}{ll}
\hline Parâmetros & Aspectos analisados \\
\hline Arquitetura da informação/ & Ordem de navegação (leitura) \\
Design de interação & Ocorrência de interação \\
& Objetos de interação \\
& Função da interação \\
& Mudança na estrutura visual \\
& Tipo de interação \\
& Nível de interatividade \\
\hline Navegação & Carregamento \\
& Ferramentas para auxiliar na navegação \\
& Navegação interna às telas \\
& Mecanismo de auxílio de identificação de elementos sensíveis \\
& Elementos sensíveis \\
Ligações entre as telas & Indicadores de localização \\
& Feedback \\
\hline
\end{tabular}

\subsection{Ensaio de interação}

O ensaio de interação abordou preferência e satisfação dos usuários, com ênfase qualitativa e procedimentos assistidos, em que os usuários foram acompanhados durante toda aplicação. O ensaio foi realizado com 14 usuários e abordagem participativa, em que eles puderam explorar livremente os infográficos, fazendo comentários e perguntas a qualquer tempo.

A estrutura do ensaio de interação foi composta por observação, questionário e entrevista semi-estruturada. Os infográficos foram mostrados aos usuários no celular da pesquisadora, já abertos e parcialmente carregados. O ensaio contou com questionário de identificação do usuário (e expectativa quanto à infografia mobile), questionário de preferência e satisfação (a ser respondido após cada infográfico mostrado), e com roteiro semi-estruturado para entrevista. Visou-se observar como os usuários interagiam com os infográficos selecionados e identificar possíveis dificuldades. Concomitantemente, havia possibilidade de verbalização simultânea da exploração, bem como realização de perguntas. Já a entrevista teve objetivo de elucidar possíveis pontos que não foram esclarecidos após a observação e o questionário. Visava saber como os usuários interagiram e identificar as preferências com relação aos infográficos e mecanismos de interação.

A amostra dos participantes do ensaio de interação foi aleatória simples, por fácil acesso e conveniência. O foco consistiu em usuários de smartphones já familiarizados com o suporte e que não fossem da área de Design, pois buscava-se a visão do usuário - externa à área e não do designer/desenvolvedor. 
Com relação à amostra de infográficos do Ensaio de interação, foram selecionados três representantes da amostra do estudo analítico, que apresentaram maior número de mecanismos de interação. Foram utilizados os seguintes infográficos:

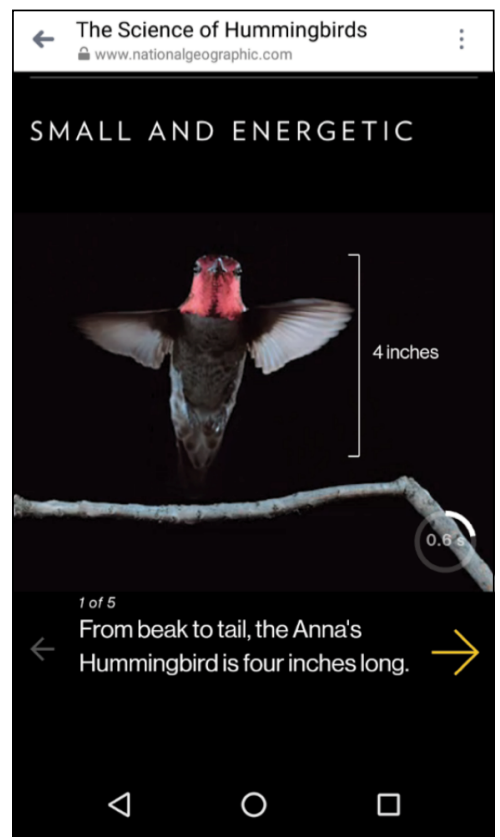

Figura 4 Infográfico 1: The Science of Hummingbirds. Fonte: Printscreen do infográfico The Science of Humming Birds.

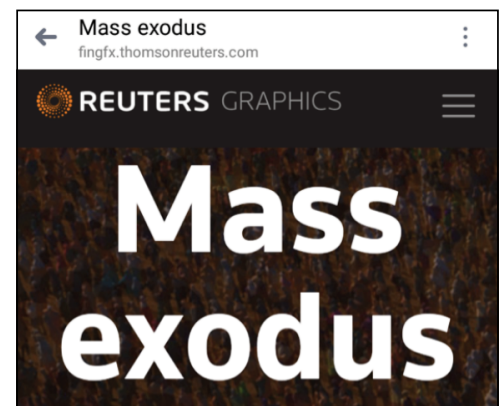

The scale of the Rohingya crisis

Hundreds of thousands of Rohingya Muslims have fled to neighboring Bangladesh since violence erupted in Myanmar's Rakhine state on August 25.

QSTCPTEMBER 21, 2017

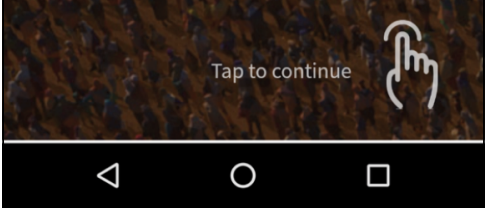

Figura 5 Infográfico 2: Mass exodus. Fonte: Printscreen do infográfico Mass exodus.

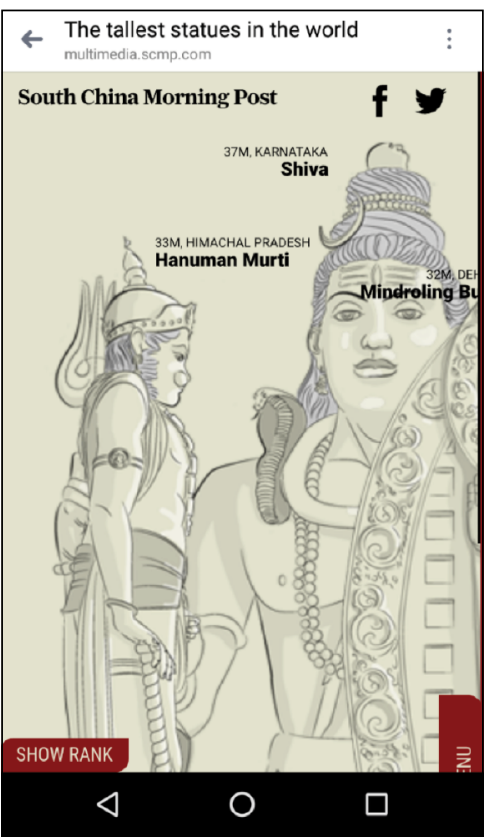

Figura 6 Infográfico 3: The tallest statues in the world. Fonte: Printscreen do infográfico The tallest statues in the world.

3.3 Estratégia de análise de dados

A análise dos dados coletados na pesquisa foi realizada utilizando como base a estratégia proposta por Miles et al. (2014):

- Condensação dos dados: etapa em que ocorreu seleção, simplificação, abstração e transformação dos dados brutos.

- Exposição dos dados: etapa que permitiu a organização e disposição de informações que foram utilizadas para a retirada de conclusões.

- Conclusões: etapa para retirada de conclusões a partir dos dados condensados e expostos.

Os resultados gerados em cada fase da pesquisa foram reunidos, codificados e tabulados, seja por meio de tabelas, figuras, gráficos, etc.

Na sequência, foi observada a existência ou não de padrões (de paradigmas, características, preferências), e realizada comparação entre os resultados. 
A partir disso, tomando por base a interpretação e análise do conteúdo, foram estabelecidas relações entre as variáveis encontradas em cada aspecto da pesquisa (triangulação) e em cada fase (inter/intra fases), observando se os dados encontrados respondem às questões levantadas no decorrer da pesquisa e aos objetivos pré-estabelecidos.

\section{Resultados}

Inicialmente, cumpre ressaltar a existência de lacuna na literatura acadêmica quanto às recomendações para elaboração de infografia digital. Em contraste, na literatura não-acadêmica encontramos diversas recomendações. Entretanto, nenhuma é específica para infografia no suporte smartphone. Tampouco foram encontrados parâmetros para análise de infográficos mobile, nem pesquisas similares para utilizar o método como base. Na pesquisa documental foi mais fácil encontrar conteúdos e resultados mais próximos ao tema pesquisado, porém, não sendo acadêmicos, não foi possível aplicá-los diretamente no desenvolvimento da presente pesquisa. Vale salientar que a falta de fundamentação teórica acerca da infografia para smartphones é um problema significativo, visto que para realizar avaliações e experimentos empíricos faz-se necessário fundamentação adequada para construir e avaliar os estudos. Esse tema se mostra relevante dentro da área de design, porém, ainda carece de pesquisa.

Com relação ao Estudo Analítico, os infográficos foram muito parecidos entre si, dificultando categorização/codificação de paradigmas de interação. Os infográficos da amostra não possuem autonomia, estando contidos em matérias jornalísticas ou atrelados a outros recursos midiáticos, utilizam funcionalidades próprias dos smartphones sem incorporá-las em sua interface. A categoria de infográfico com maior incidência foi do tipo "animado", e a com menor incidência foi "interativo". Como multimídia incorporada, o recurso mais utilizado foi animação e vídeo, ficando restritos a esse tipo de exploração das vantagens que o smartphone oferece.

Constatou-se, ainda, diminuição de interatividade na passagem do desktop para o smartphone. O nível de interação no suporte mobile em geral é básico (apenas botão de play). Os objetos de interação presentes na amostra se limitavam a barras (de rolagem, de controle, player, etc) e botões de comando. O carregamento se dava por telas e/ou layers, e era lento em sua maioria. Todos os itens do protocolo poderiam se aplicar aos infográficos, porém, na amostra, a maioria não apareceu.

O Ensaio de interação foi a parte mais rica da pesquisa. Houve dificuldades nas interações e navegação. A maioria dos participantes demonstrou desconforto em aguardar o carregamento dos infográficos e não explorou os "recursos extras" que alguns infográficos ofereciam. Os usuários pediram "dinamismo" e "botões exploratórios". Porém, quando esses itens estavam presentes, nem sempre foram explorados. 
Talvez as formas de apresentação, interação e navegação não estejam adequadas aos smartphones, tornando a navegação cansativa e a interação difícil e confusa, causando insatisfação. O quadro a seguir mostra a comparação breve entre os resultados dos três infográficos utilizados no ensaio de interação:

Quadro 4 Quadro-síntese dos resultados dos infográficos utilizados no Ensaio de Interação. Fonte: elaborado pelas autoras (2019).

(Continua)

Estudo analítico
Contexto da apresentação: independente
Categoria: animado e interativo
Adaptatividade: não existe
Ordem de navegação: linear
Ocorrência de interação: animação / qualquer lugar
da tela
Objetos de interação: menu, botões, abas, links,
barra de controle, barra de rolagem, controle de
animações, players, botões de avanço e retrocesso
Mudança na estrutura visual: atributos gráficos,
posição espacial, inclusão
Tipo de interação: instrução
Interatividade: baixa

Navegação interna: rolagem (vertical), avanço linear Auxílio de identificação de elementos sensíveis: instrução de navegação, links sinalizados

Elementos sensíveis: globais, sempre aparentes, representações esquemáticas

Ligações entre as telas: descendente, lateral, retorno às telas já visitadas

\section{Ensaio de interação}

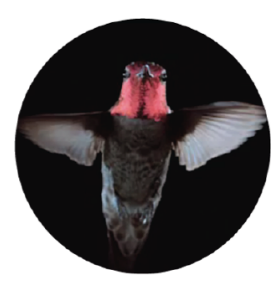

THE SCIENCE OF HUMMING BIRDS

Está: acima da expectativa

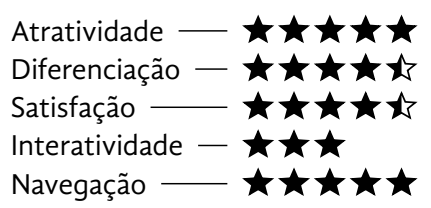

Melhorias: cores e interações
Contexto da apresentação: independente Categoria: animado e interativo

Adaptatividade: não existe

Ocorrência de interação: -

Objetos de interação: menu, botões, abas, links, barra de controle. Permite zoom

Mudança na estrutura visual: atributos gráficos, inclusão

Tipo de interação: instrução

Interatividade: baixa

Navegação interna: rolagem (horizontal) Auxílio de identificação de elementos sensíveis: instrução de navegação

Elementos sensíveis: globais

Ligações entre as telas: descendente, retorno às telas já visitadas

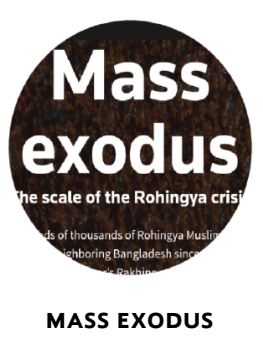

Está: dentro da expectativa

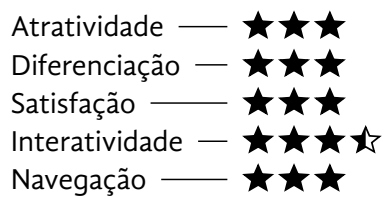

Melhorias: interatividade, localização, navegação, botão de voltar 
Quadro 4 Quadro-síntese dos resultados dos infográficos utilizados no Ensaio de Interação. Fonte: elaborado pelas autoras (2019).

(Conclusão)

\begin{tabular}{|c|c|}
\hline Estudo analítico & Ensaio de interação \\
\hline \multicolumn{2}{|l|}{$\begin{array}{l}\text { Contexto da apresentação: independente } \\
\text { Categoria: animado e interativo }\end{array}$} \\
\hline \multicolumn{2}{|l|}{ Adaptatividade: não existe } \\
\hline \multicolumn{2}{|l|}{$\begin{array}{l}\text { Ordem de navegação: linear } \\
\text { Ocorrência de interação: animação / qualquer lugar } \\
\text { da tela }\end{array}$} \\
\hline \multicolumn{2}{|l|}{$\begin{array}{l}\text { Objetos de interação: menu, botões, abas, links, } \\
\text { barra de controle, barra de rolagem, controle de } \\
\text { animações, players, botões de avanço e retrocesso }\end{array}$} \\
\hline $\begin{array}{l}\text { animações, players, botões de avanço e retrocesso } \\
\text { Mudança na estrutura visual: atributos gráficos, }\end{array}$ & Está: abaixo da expectativa \\
\hline posição espacial, inclusão & Atratividade $-\star \star \longleftrightarrow$ \\
\hline Tipo de interação: instrução & Diferenciação $-\star \star \star \succ$ \\
\hline Interatividade: baixa & Satisfação $\backslash \star \boldsymbol{\downarrow}$ \\
\hline $\begin{array}{l}\text { Navegação interna: rolagem (vertical), avanço linear } \\
\text { Auxílio de identificação de elementos sensíveis: }\end{array}$ & $\begin{array}{l}\text { Interatividade 一 } \\
\text { Navegação - }\end{array}$ \\
\hline instrução de navegação, links sinalizados & Melhorias: tudo \\
\hline \multicolumn{2}{|l|}{$\begin{array}{l}\text { Elementos sensíveis: globais, sempre aparentes, } \\
\text { representações esquemáticas }\end{array}$} \\
\hline $\begin{array}{l}\text { Ligações entre as telas: descendente, lateral, retorno } \\
\text { às telas já visitadas }\end{array}$ & \\
\hline
\end{tabular}

Os resultados acerca de preferência/satisfação dos usuários quanto aos exemplos do ensaio de interação foram os infográficos 1 , 2, 3 respectivamente e corroboram estudos de Miranda (2013) e Andrade (2014) sob o viés descritivo e o "nível ideal" de interatividade. Corroboram Barrio (2014), quanto ao projeto específico para infográficos em smartphone. As interações não são exploradas de forma satisfatória, permanecendo no paradigma de infográficos impressos, conforme Cairo (2008). As questões de interação / navegação pedem mais atenção.

Comparando-se os resultados do estudo analítico com os do ensaio de interação, percebemos que são poucos os mecanismos de interação presentes na amostra. Como exemplo, tem-se o uso de barras de rolagem, menus, botões e links. Metade da amostra teve "baixa interatividade" e nenhum dos infográficos foi classificado como tendo alta interatividade. As interações, quando ocorriam, eram do tipo instrucional e apenas $1 / 3$ da amostra apresentou elementos sensíveis. Os infográficos com maior consistência na estrutura dos elementos e dos recursos utilizados, que surpreendem positivamente o leitor com gifs e vídeos, foram preferidos pelos usuários; os infográficos que utilizam recursos e conteúdos em demasia acabaram sendo confusos e cansativos, mesmo utilizando diversos recursos exploratórios; os usuários pedem por interatividade e animação, por peças simples e intuitivas. É necessário equilíbrio entre o grau de interatividade e simplicidade. Os usuários interagiram com os infográficos mais ricos em interações de forma satisfatória, sendo atraídos e demonstrando interesse pela exploração 
e conteúdo. Já com o segundo infográfico, que não teve o mesmo cuidado com o uso dos elementos interativos e recursos utilizados, os usuários acabam se sentindo "perdidos" e cansaram na navegação.

\section{Conclusões}

Considera-se que essa pesquisa atingiu os objetivos (em nível exploratório) a que se propôs. A seguir, apresentamos uma síntese das conclusões com relação aos infográficos no suporte smartphone:

- são poucos os mecanismos de interação presentes;

- em geral, possuem "baixa interatividade" e do tipo instrucional;

- apresentam poucos elementos sensíveis;

- infográficos que utilizam recursos e conteúdos em demasia acabam confundindo e cansando os usuários, mesmo se utilizarem diversos recursos exploratórios;

- infográficos que apresentam maior consistência na estrutura dos elementos adotados, dos recursos utilizados e que surpreendem positivamente o leitor com gifs e vídeos, acabaram sendo a preferência dos usuários;

- há necessidade de melhor estruturar e planejar interações, modificar layouts, e acrescentar interatividade com parcimônia.

- Já com relação aos usuários, as principais conclusões foram:

- os usuários pedem por interatividade e animação mas também por peças que sejam simples e intuitivas;

- fica clara a percepção dos usuários sobre a inadequação dos infográficos aos smartphones;

- há interesse pela exploração e conteúdo, mas também ficam "perdidos" e cansados da navegação.

Como desdobramentos da presente pesquisa, vislumbra-se vastas possibilidades visto se tratar de tema pouco explorado. Sugere-se rever algumas técnicas utilizadas nessa pesquisa; aprofundar os estudos na área visando validar ou não os resultados encontrados; e adotar outras abordagens de análise para as pesquisas dessa temática. Há muito a ser investigado e discutido sobre a infografia para smartphones, sobre as especificidades desse suporte e dos materiais para ele desenvolvidos, e sobre a interação móvel em smartphones, além de diversos outros temas. São exemplos:

- diferenciação da infografia através das layers de informação;

- aspectos constituintes dos infográficos em smartphones;

- interface dos infográficos para esse suporte;

- a relação entre idade do usuário × satisfação $\times$ interatividade, levando em consideração o background desses usuários que podem estar mais ou menos acostumados a paradigmas de infográficos impressos, em relação aos digitais. 


\section{Referências}

ALVES, Y. M.; ROCHA, L. V. Jornalismo em dispositivos móveis: uma análise do conteúdo da revista Superinteressante. Temática, João Pessoa, ano 11, n. 5, p. 61-76, 2015.

AMARAL, R. C. G. Infográfico jornalístico de terceira geração: análise do uso da multimidialidade na infografia. 2010. Dissertação (Mestrado em Jornalismo) Centro de Comunicação e Expressão, Universidade Federal de Santa Catarina, Florianópolis, 2010.

ANDRADE, R. C. Infográficos animados e interativos em saúde: um estudo sobre a compreensão de notícias. 2014. Dissertação (Mestrado em Design) - Setor de Artes, Comunicação e Design, Universidade Federal do Paraná, Curitiba, 2014. ANDRUCHAK, M. A.; SOUZA, C. B. M. Interface gráfica do usuário em telas reduzidas. Ergotrip Design, Natal, n. 1, p. 302-309, 2015.

BARRIO, E. A. Nuevos soportes para contenidos informativos y sus implicaciones: breve acercamiento a modelos de software y características de los contenidos web. Historia y Comunicación Social, Valladolid, v. 19, n. esp., p. 559-570, 2014.

CARVALHO, J.; ARAGÃO, I. Infografia: conceito e prática - fundamentais da infografia e do design. InfoDesign, São Paulo, v. 9, n. 3, p. 160-170, 2012.

CAIRO, A. Infografia 2.0: visualización interactiva de información en la prensa. Madrid: Alamut, 2008.

COLLE, R. Infografía: tipologías. Revista Latina de Comunicación Social, La Laguna, n. 57, 2004. Disponível em: http://catedranaranja.com.ar/wp/wpcontent/uploads/Infografia-Colle.pdf. Acesso em: 20 jan. 2017.

CYBIS, W.; BERTIOL, A. H.; FAUST, R. Ergonomia e usabilidade: conhecimentos, métodos e aplicações. São Paulo: Novatec Editora, 2007.

FASSINA, U. A infografia como recurso comunicacional no processo de aquisição de informação e compreensão de tipografia. 2011. Dissertação (Mestrado em Comunicação) - Centro de Educação, Comunicação e Artes, Universidade Estadual de Londrina, Londrina, 2011.

FONSECA, D.; NAVARRO, I.; REDONDO, E. Designing architectural images for small screen devices in function of user experience. In: IBERIAN CONFERENCE ON information systems and technologies, 6., 2011, Chaves. Proceedings [...]. [S.1.]: Institute of Electrical and Electronics Engineers, 2011. p. 1-6. GONZÁLEZ-PACANOWSKI, T.; MEDINA, P. Valor comunicacional de la infografia. El profesional de la información, León, v. 18, n. 4, p. 413-420, 2009. DOI: 10.3145/epi.2009.jul.o8.

GIANNELlA, J. R. Dispositivo infovis: interfaces entre visualização da informação, infografia e interatividade em sítios jornalísticos. 2014. Dissertação (Mestrado em Ciências da Comunicação) - Escola de Comunicações e Artes, Universidade de São Paulo, São Paulo, 2014.

KRONE, C. Validação de heurísticas de usabilidade para celulares touchscreen. Florianópolis: Grupo de Qualidade de Software/INCod/UfSC, 2013.

LIMA, R. C. Análise da infografia jornalística. 2009. Dissertação (Mestrado em Design) - Escola Superior de Desenho Industrial, Universidade do Estado do Rio de Janeiro, Rio de Janeiro, 2009. 
LÓPEZ, J. L. G., ROYO, T. M., LABORDA, J. G. F., CALVO, G. Methods of adapting digital content for the learning process via mobile devices. Procedia, [S.1.], v. 1, n. 1, p. 2673-2677, 2009.

MIRANDA, F. Animação e interação na infografia jornalística: uma abordagem do Design da Informação. 2013. Dissertação (Mestrado em Design) - Setor de Artes, Comunicação e Design, Universidade Federal do Paraná. Curitiba, 2013. MIRANDA F.; ANDRADE R, C. Pensar Infográfico: uma proposta de ensino introdutório de infografia sob a perspectiva da linguagem gráfica. InfoDesign, São Paulo, v. 14, n. 3, p. 374-396, 2017.

MILES, M.B., HUBERMAN, A. M., SALDAÑA, J. Qualitative data analysis: a methods sourcebook. 3. ed. Thousand Oaks: Sage, 2014.

MORAES, A. Infografia: história e projeto. São Paulo: Blucher, 2013.

PADOVANI, S.; NAPO, P. R. Sistemas de navegação em smartphones: um guia teóricoprático de design. In: Navegação em smartphones: uma abordagem centrada no usuário (relatório final de projeto - CNPq 300641/2012-5). Curitiba, UFPR, 2015. 63 p.

PADOVAni, S. PUPPI, M., SCHLEMmer, A. Modelo descritivo para interfaces de aplicativos em smartphones. InfoDesign, São Paulo, v. 17, n. 1, p. 123-143, 2017. PRIMO, A. Vlog Número Primo - episódio 1: jornalismo para iPad e Kindle. 2011. Disponível em: https://youtu.be/YAloiFvLvV8. Acesso em: 15 jan. 2018. REILLY, S. The need to help journalists with data and information visualization. IEEE Computer Graphics and Applications, [S.1.], v. 37, n. 2, p. 8-10, 2017. RIBAS, A. C.; VANZIN, T.; ULBRICHT, v. Design responsivo e acessibilidade para dispositivos moveis: uma revisão sistemática de literatura. Estudos em Design, Rio de Janeiro, v. 23, n. 3, p. 27-35, 2015.

RODRIGUES, A. A. Infografia interativa em base de dados no jornalismo digital. 2009. Dissertação (Mestrado em Comunicação e Cultura Contemporâneas) - Faculdade de Comunicação Social, Universidade Federal da Bahia, Salvador, 2009.

RODRIGUES, A. A. A narrativa infográfica em plataformas móveis: o caso das Revistas Superinteressante e Galileu adaptadas para iPad. In: ENCONTRO NACIONAL DE PESQUISADORES EM JORNALISMO, 9., 2011, Rio de Janeiro. Anais [...]. Rio de Janeiro: Universidade Federal do Rio de Janeiro, 2011. SAlaverría, R. Convergencia de medios. Chasqui, Quito, n. 81, p. 32-39, 2003. Disponível em: http://revistachasqui.org/index.php/chasqui/article/ view/1471. Acesso em: 14 dez. 2017.

TIBES, C. M. S.; DiAS, J. D., ZEM-MASCARENhas, s. H. Aplicativos móveis desenvolvidos para a área da saúde no Brasil: revisão integrativa da literatura. Reme, Belo Horizonte, v. 18, n. 2, p. 471-478, 2014.

WALLER, R. Graphic literacies for a digital age: the survival of layout. The Information Society, [S.1.], v. 28, n. 4, p. 236-252, 2012. DOI: 10.1080/01972243.2012.689609. 


\section{Sobre as autoras}

\section{Evelyn Henkel}

evelyn.colore@gmail.com

Universidade Federal do Paraná, Departamento de Design

Rua General Caneiro, 460, 8º andar, Curitiba, PR, Brasil CEP: 80060-150

\section{Stephania Padovani}

stephania.padovani@gmail.com

Universidade Federal do Paraná, Departamento de Design

Rua General Caneiro, 460, 8º andar, Curitiba, PR, Brasil CEP: 80060-150

Artigo recebido em/Submission date: 27/5/2019

Artigo aprovado em/Approvement date: 10/12/2020 